\title{
Lung function at school age in infants with lower respiratory tract infections with and without wheezing: a birth cohort study.
}

Franca Rusconi ${ }^{1}$, Enrico Lombardi ${ }^{2}$, Elena Spada ${ }^{3}$, Sonia Brescianini ${ }^{4}$, Martina Culasso ${ }^{5}$, Francesca Di Toro ${ }^{6}$, Antonella Frassanito ${ }^{7}$, Lorenzo Richiardi ${ }^{8}$, Luca Ronfani ${ }^{6}$, Ileana Stella $^{9}$, and Luigi Gagliardi ${ }^{10}$

${ }^{1}$ Azienda USL Toscana nord ovest

${ }^{2}$ Meyer Pediatric University Hospital

${ }^{3} 1$ Epidemiology Unit, Meyer Children's University Hospital, Florence, Italy

${ }^{4}$ Istituto Superiore di Sanità

${ }^{5}$ Department of Epidemiology of the Regional Health Service Lazio

${ }^{6}$ IRCCS Materno Infantile Burlo Garofolo

${ }^{7}$ Policlinico Umberto I

${ }^{8}$ University of Turin

${ }^{9}$ Maria Vittoria Hospital

${ }^{10}$ Azienda USL Toscana nord ovest Sede Pisa

November 12, 2021

\begin{abstract}
Objective: To evaluate the relationship between lower respiratory tract infections (LRTI), in the first 2 years of life and lung function at school age in the Piccolipiù birth cohort (Italy). Methods: Data on LRTI (doctor diagnosis of bronchitis, bronchiolitis, pneumonia) and wheezing ([?]3 episodes or a diagnosis of asthmatic bronchitis) in the first 2 years of life were obtained from parental questionnaires. Lung function was assessed at 7 years by spirometry and forced volume vital capacity (FVC), forced expiratory volume in one second (FEV1), FEV1/FVC, forced expiratory flow between 25 and $75 \%$, and at $75 \%$ of FVC (FEF2575 and FEF75) were reported as z-scores. The associations between LRTI and spirometric variables were estimated with linear regression models. Results: Among 877 children studied, $22.1 \%$ had LRTI only, $5.4 \%$ wheezing only, 13.2\% had both, and 59.3\% had neither LRTI nor wheezing. Children with LRTI had lower FVC and FEV1 than children without (z-score differences: -0.18 (95\% Confidence Intervals, $-0.31 ;-0.06)$ and $-0.15(0.27 ;-0.03))$. When children were stratified by history of both LRTI and wheezing, there was no association between LRTI only and spirometric values. Conversely, having had both LRTI and wheezing was inversely associated with all lung function measures: z-score differences of $-0.24(0.42 ;-0.07) ;-0.42(-0.59 ;-0.24)$; -0.25 (-0.41; -0.08); -0.37 (-0.54; -0.21); -0.30 (-0.46; -0.14) for FVC, FEV1, FEV1/FVC, FEF25-75 and FEF75, respectively. Conclusion: Infants with wheezing and LRTI, but not those with LRTI only, had reduced lung function at school-age.
\end{abstract}

\section{Hosted file}

main_document.doc available at https://authorea.com/users/445688/articles/545128-lungfunction-at-school-age-in-infants-with-lower-respiratory-tract-infections-with-andwithout-wheezing-a-birth-cohort-study

\section{Hosted file}

table1.docx available at https://authorea.com/users/445688/articles/545128-lung-function-at- 
school-age-in-infants-with-lower-respiratory-tract-infections-with-and-without-wheezinga-birth-cohort-study

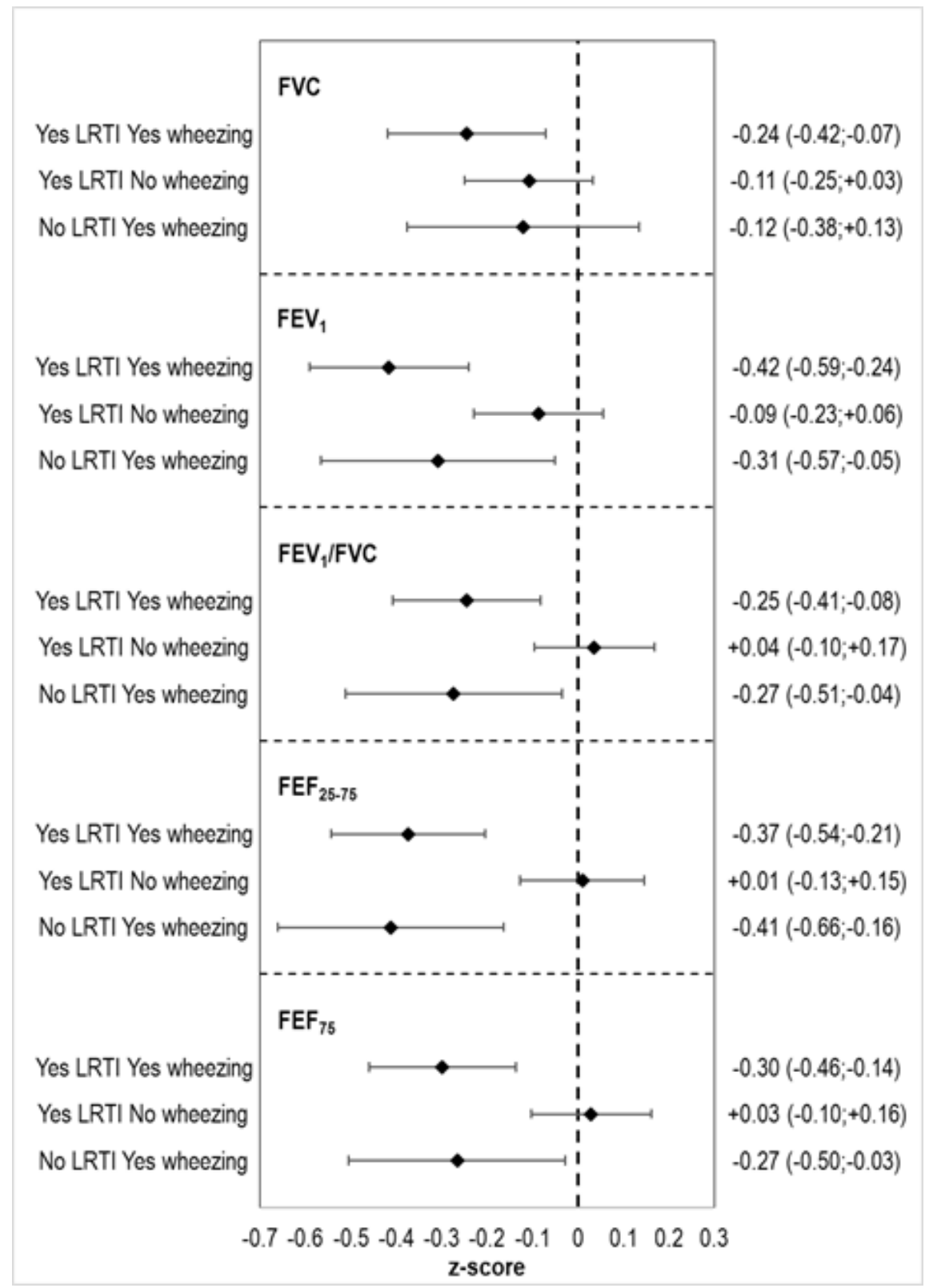

